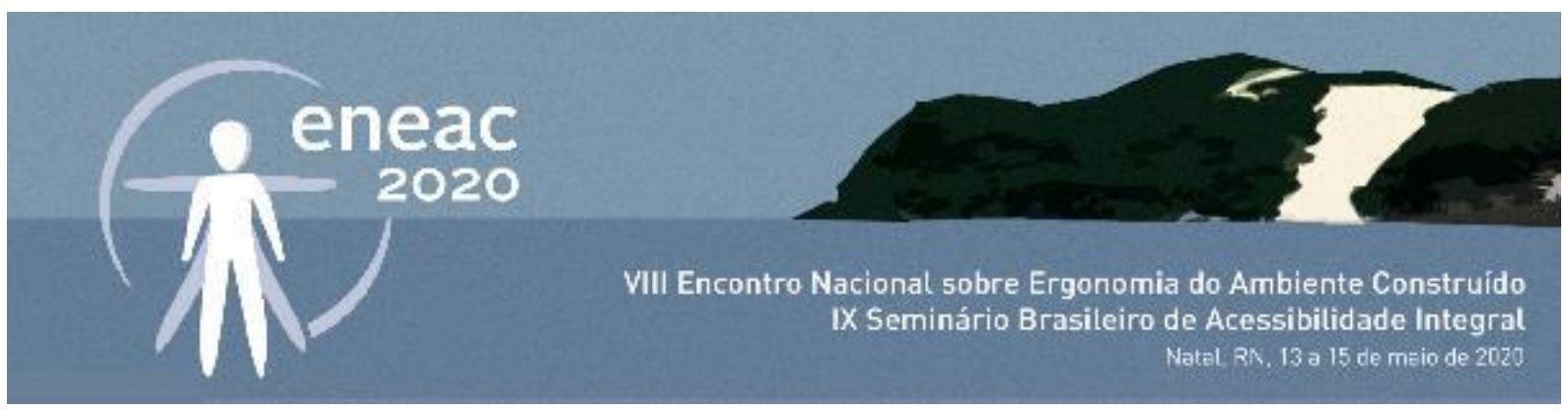

\title{
Cor e orientação espacial no ambiente hospitalar: as contribuições da pesquisa em Ergonomia
}

\author{
Color and spatial orientation in the healthcare environment: the \\ contributions of Ergonomics research
}

\begin{abstract}
MÁRCIA MOREIRA RANGEL
Doutora, Instituto Federal de Educação, Ciência e Tecnologia do Sudeste de Minas Gerais/ campus Juiz de Fora, marcia.rangel@ifsudestemg.edu.br
\end{abstract}

CLÁUDIA MONT'ALVÃO

Doutora, Programa de Pós-graduação em Design PUC-Rio - Pontifícia Universidade Católica do Rio de Janeiro, cmontalvao@puc-rio.br

\begin{abstract}
RESUMO
Inicia-se esse trabalho com um breve panorama do desenvolvimento da ergonomia e sua aplicação nos estudos do ambiente construído. Faz-se então uma reflexão sobre temas pertinentes aos campos da Arquitetura, do Design de interiores e do Design Gráfico, pois aponta premissas inerentes ao usuário, ao projeto do ambiente construído e à cor, pertinentes à uma interação que auxilie a orientação espacial. Reflete sobre a articulação desses temas. Visa-se contribuir para a pesquisa em Design, uma vez que a convergência de saberes dentre essas disciplinas, articulados pelo Design, ainda é objeto pouco discutido. Como exemplo da possibilidade da aplicação dos conceitos e princípios ergonômicos, discute-se o conhecimento do ambiente hospitalar, as tarefas ali executadas e os aspectos de uso do ambiente para a definição de estratégias do uso da cor na orientação espacial. Essa abordagem permite ao leitor entender, a partir da fundamentação teórica, que a cor pode ser utilizada como ferramenta de orientação e sinalização, e não meramente um adereço com fins estéticos. O principal objetivo do texto é ampliar tal discussão para prover subsídios para a projetação de ambientes adequados às necessidades reais de seus usuários.
\end{abstract}

PALAVRAS-CHAVE: Ergonomia do ambiente construído, Cor, Ambiente hospitalar

\section{ABSTRACT}

This work begins with a brief overview of the development of ergonomics and its application in studies of the built environment. A reflection is made on themes relevant to the fields of Architecture, Interior Design and Graphic Design, as it points out premises inherent to the user, the design of the built environment and color, pertinent to an interaction that helps spatial orientation. Reflects on the articulation of these themes. This study aims to contribute to research in Design, since the convergence 


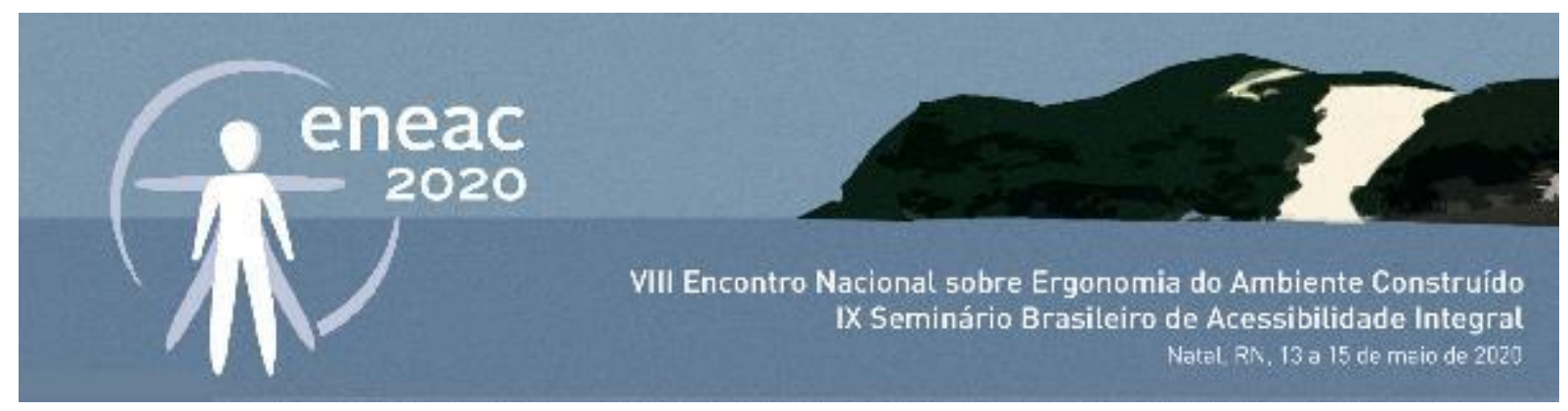

of knowledge among these disciplines, articulated by Design, is still it is little discussed. As an example of the possibility of applying ergonomic concepts and principles, we discuss knowledge of the healthcare environment, the tasks performed there and the aspects of using the environment to define strategies for the use of color in signage. This approach allows the reader to understand, from the theoretical basis, that color can be used as a tool for guidance and signage, and not merely an adornment for aesthetic purposes. The main objective of the text is to increase this discussion, in order to provide subsidies for the design of environments adapted to the real needs of its users.

KEYWORDS: Ergonomics of the built environment, Color, Hospital environment

\section{INTRODUÇÃO}

As pesquisas em Ergonomia, principalmente em nível de Pós-Graduação tem-se se mostrado cada vez mais interdisciplinares. Algumas áreas já são amplamente exploradas, e há vários anos, por conta não só da criação da Ergonomia como disciplina, mas também pela sua expansão. A Ergonomia é facilmente entendida como aplicável ao estudo de produtos e processos (tais como ambientes de trabalho, pegas e empunhaduras, produtos de uso cotidiano), de sistemas humano-computador (softwares, ambientes virtuais de aprendizagem, aplicativos), e de sistemas de informação (manuais de instrução, avisos e advertências). Por outro lado, pode-se dizer que o estudo da aplicação de conceitos ergonômicos no ambiente construído ainda é recente, frente a todas essas áreas.

Tem-se como referência no assunto a primeira Tese de Doutorado defendida no Brasil da professora e pesquisadora Vilma Villarouco, em 2001, a qual propõe um instrumento de avaliação cujos resultados demonstram um melhor entendimento dos aspectos cognitivos e perceptivos na interação usuário x ambiente construído (VILLAROUCO, 2001). Em 2007, avançando em suas pesquisas, Vilma Villarouco apresentou, em uma mesa redonda no primeiro ENEAC, a metodologia ergonômica do ambiente construído (MEAC) onde etapas da Análise Ergonômica do Trabalho (Analise Global do Ambiente, Identificação da Configuração Ambiental e Diagnostico Ergonômico do Ambiente) são aplicadas de forma conjunta a uma análise de Percepção ambiental, através da aplicação da técnica da Constelação de atributos.

De lá para cá, muitos pesquisadores têm-se destacado na área, com produção permanente na pósgraduação, relacionando a Ergonomia com a percepção ambiental, com a análise da tarefa, com a discussão sobre o projeto de espaços de trabalho, configurando assim essa área que agora chamamos Ergonomia do Ambiente Construído.

No Brasil, pode-se dizer que a área está consolidada justamente pela diversidade e alcance das pesquisas da pós-graduação. Como consequência, vê-se a discussão trazida também para o âmbito da graduação. Este percurso pode ser observado, desde 2007, com a realização de encontros bianuais, com pesquisadores, docentes e discentes de pós-graduação e graduação, o ENEAC, Encontro Nacional de Ergonomia do Ambiente Construído e Seminário Brasileiro de Acessibilidade Integral (MONT'ALVÃO; VILLAROUCO, 2011)

Citando a pesquisadora Anamaria de Moraes (2004, p. 8), "no termo ambiental cabem aspectos que contemplam questões amplas, como a ecologia, até aspectos mais restritos, como a iluminação e temperatura de um dado ambiente." As discussões sobre as questões ambientais ainda consideram as premissas do Design Universal ou transgeracional e da acessibilidade. Além disso, aliam-se aqui os 


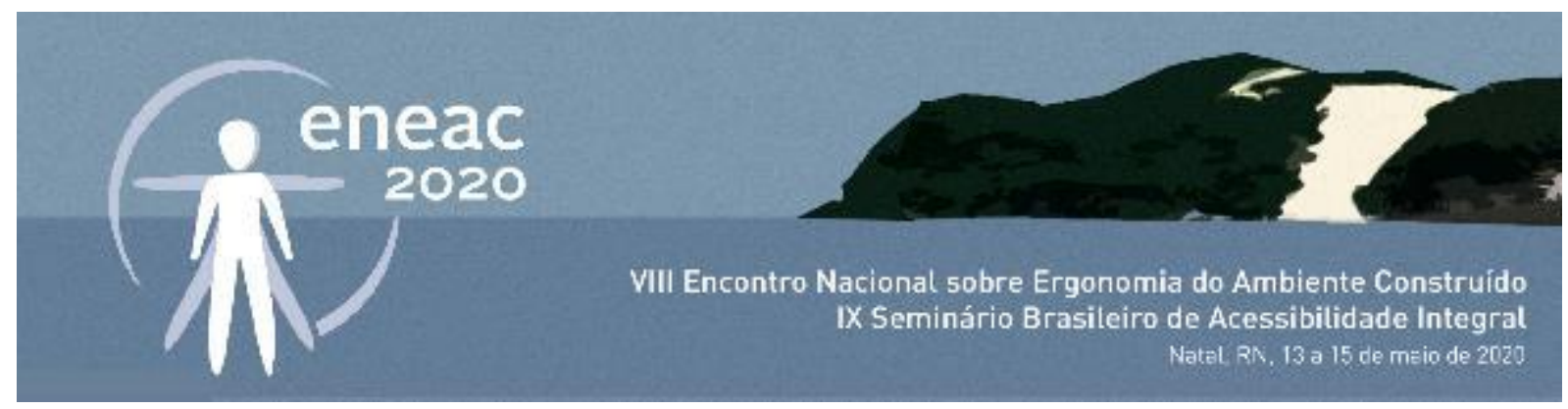

parâmetros básicos da Ergonomia: conforto, segurança e bem-estar (MORAES, 2004, p. 9).

Nesse contexto, as pesquisas da Ergonomia do ambiente construído lidam com muitas variáveis relativas ao usuário, ao ambiente construído investigado e ao tema que irá propiciar a interação foco da pesquisa.

Esse trabalho apresenta como exemplo das características e interações da Ergonomia com o Ambiente Construído, um estudo sobre as aplicações da Ergonomia no ambiente hospitalar. Trata da interação usuário $\mathrm{x}$ ambiente construído hospitalar $\mathrm{x}$ cor. Aponta premissas inerentes ao usuário, ao projeto do ambiente construído e à cor, pertinentes à uma interação que auxilie a orientação espacial. Reflete sobre a articulação desses temas.

Não é um relato de pesquisa prática/ aplicada, como muitas que encontramos desenvolvidas nas linhas de pesquisa em Ergonomia nos diversos Programas de Pós-Graduação espalhados pelo Brasil. Trata-se de uma reflexão sobre como tarefas, sinalização e cores, temas tão próprios da prática do Design Gráfico, de Interiores e Ambiental devem ser (re)pensados. O conhecimento produzido na Academia deve servir (também) como fundamentação da prática profissional.

\section{CARACTERIZANDO O PROBLEMA}

O ser humano é o centro da concepção do ambiente construído, uma vez que os projetos, tanto de arquitetura quanto de design, são (ou deveriam ser) desenvolvidos para atenderem as necessidades das pessoas. Para tal, tanto a pessoa (usuário do espaço) quanto o espaço devem ser compreendidos em suas especificidades.

O usuário interage ativamente com o ambiente construído como um ser individual e sensorial, conectado aos componentes de seu mundo, e deve ser entendido como uma entidade tridimensional: corpo/mente/espírito que reage sempre holisticamente com as dimensões somática, mental e espiritual (FRANKL apud MEERWEIN et al., 2007).

$\checkmark$ Dimensão somática refere-se a um processo físico/orgânico/celular das funções corporais biológica/fisiológica. Ativa o centro de ação física e material.

$\checkmark$ Dimensão mental envolve as emoções e sentimentos. Vinculada às características sociais e padrões de conhecimentos adquiridos. Governa nossa interação intelectual e qualitativa com o ambiente.

$\checkmark$ Dimensão espiritual, agrupa as decisões autônomas e o livre-arbítrio; os interesses materiais e artístico/culturais, e as ideias criativas. Governa a interação espiritual, sensorial e cognitiva com o ambiente.

O ambiente construído abarca a arquitetura e os diversos elementos de design que irão estruturar o espaço dos eventos e das interações humanas. É definido pela forma, materiais, luz e cor, mas se apresenta como um espaço vivido a partir de sua conexão com o usuário. Esse espaço vivencial está além dos fatores estruturais objetivos e quantificáveis.

Segundo Meerwein et al. (2007), a performance e o efeito de um espaço dependem, principalmente, das metas subjetivas do usuário, da experiência pessoal e expectativas, podendo ser descrita pelos fatores de uso. Assim, o espaço possui questões materiais e imateriais, que o tornam em "espaço 


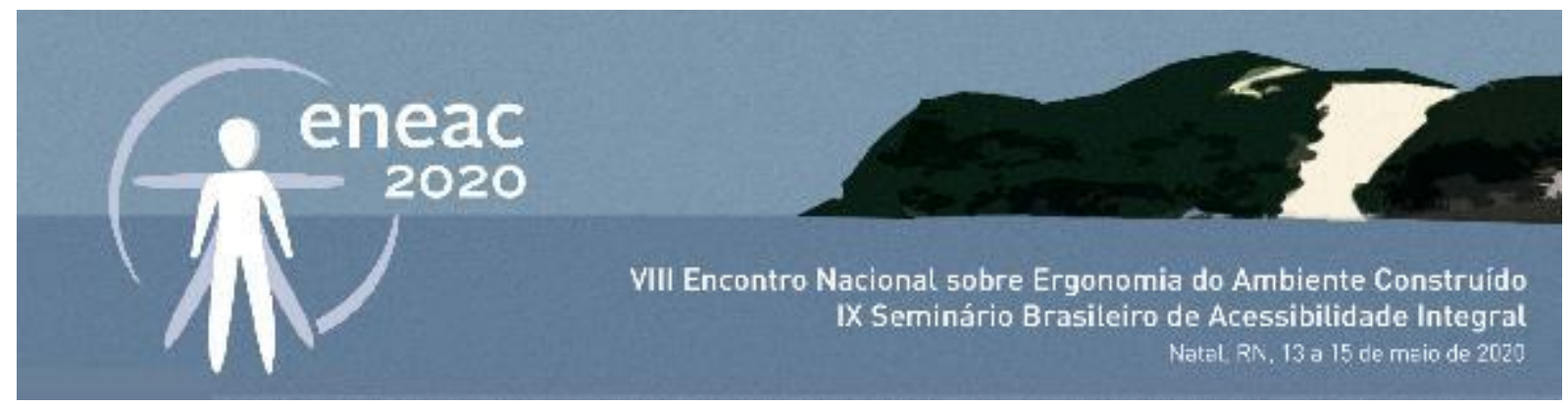

percebido" descrito pela sua imagem, potencialidade percebida, originalidade, valores simbólicos, atmosfera, etc. Esse espaço vivido e experimentado pode tanto facilitar quanto impedir as relações interpessoais e com o ambiente construído.

Para Meerwein et al. (2007, p.63),

O efeito simbólico, o criativo e a impressão gerada pelo espaço determinam como as pessoas se sentem dentro dele [...]. Também afetam a forma como se identificam, se apropriam e comportam-se em e dentro das atrações do espaço, e como eles atuam individual e socialmente.

Meerwein et al. (2007) pontuam que um perigo da fase de planejamento da forma arquitetônica é a racionalidade, pois é a mais fácil de alcançar. Já o valor emocional do espaço é frequentemente ignorado, uma vez que os projetistas teriam que lidar com opiniões subjetivas dos usuários, aspectos sociais, sensações psicológicas e estruturas fisiológicas. Essas questões devem fazer parte dos valores, além das habilidades, dos projetistas (LAWSON, 2011), para que obtenham a devida importância no projeto.

Os autores Meerwein et al. (2007) ainda apontam três pontos importantes do complexo repertório de meios (recursos) do projeto arquitetônico: (1) as propriedades dos elementos; (2) as relações entre os elementos e (3) as relações entre os elementos e as pessoas que as percebem. Nesse sentido, entende-se a partir de Rangel (2016), que esses três recursos inerentes ao ambiente construído são também pertinentes aos projetos de design vinculados ao ambiente em questão.

De todos os ambientes construídos, o hospitalar é considerado o mais complexo (RANGEL, 2016) e talvez aquele em que mais se percebam as questões emocionais e as necessidades de bem-estar, $\mathrm{e}$ de coibir o estresse vinculados a ele. A complexidade do ambiente construído hospitalar está vinculada ao tamanho, aos inúmeros setores pertinentes aos diversos serviços oferecidos, ao grande e diversificado número de usuários, e aos aspectos simbólicos e emocionais que permeiam as situações de dor e doença.

Os hospitais, segundo Marcos (2004, apud REQUENA, 2019, p.17), possuem "cômodos rigidamente definidos por sua funcionalidade", e diferentemente da casa, no ambiente construído hospitalar não há "caminho para a irrupção da desordem, da surpresa e do imprevisto". As tarefas desenvolvidas no ambiente devem ser analisadas em função de sua complexidade.

Dentre as diversas interações do usuário no ambiente construído hospitalar, a orientação espacial é muito importante, pois as pessoas precisam estar bem orientadas para poderem encontrar o seu destino no emaranhado de caminhos possíveis e em meio a um fluxo de pessoas as vezes intenso, em segurança e sem aumentar estados de ansiedade e estresse.

A cor no ambiente construído hospitalar acompanhou as diversas transformações dessas instituições ao longo dos séculos. No entanto, aqui apontam-se três marcos da cor nos hospitais (RANGEL; MONT'ALVÃO, 2012):

1. Em meados do século $X X$ o branco foi utilizado quase que de forma total nos ambientes hospitalares - tetos, pisos, paredes, mobiliário, vestimentas - independentemente da função do ambiente, e tinha como objetivo principal as questões de higiene; 


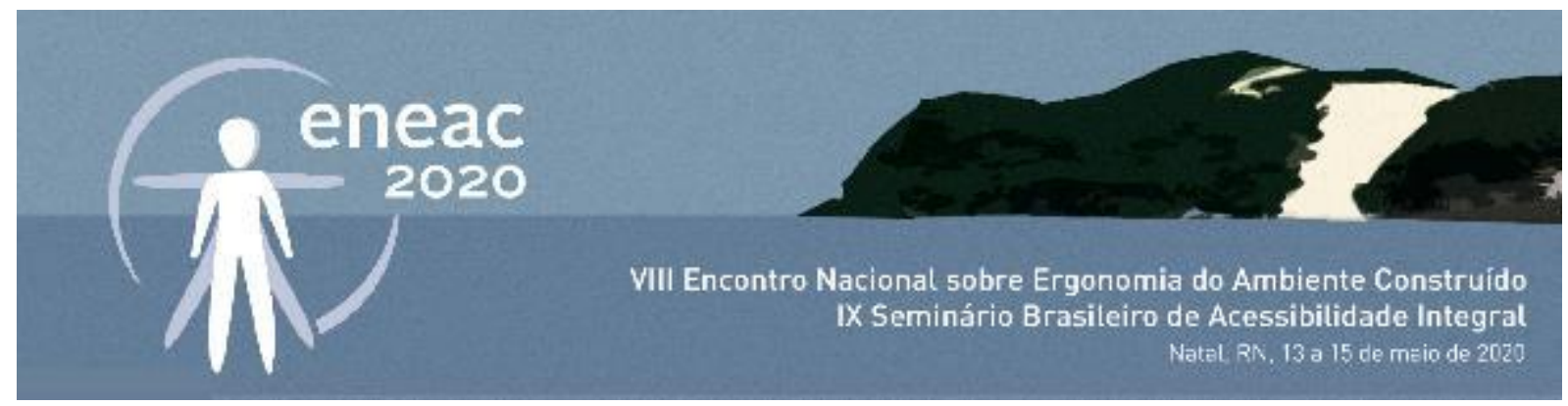

2. O avanço das pesquisas da psicologia ambiental, demonstrando a importância do ambiente na saúde dos usuários no sentido de atender seu lado emocional, fazendo com que se sinta psicologicamente mais relaxado, menos estressado. Esses estudos encontraram consonância nas pesquisas sobre as impressões negativas das pessoas relativas aos ambientes brancos, impessoais e inóspitos;

3. A diversidade cromática nos materiais contemporâneos, possibilitando ampla utilização da cor para conferir ambiências diversificadas.

Em decorrência, a cor tem seu uso cada vez mais ampliado no ambiente construído hospitalar, no entanto, devido ao número de variáveis que envolvem o uso da cor (TOFLE et al., 2004), esse importante recurso da comunicação visual (DONDIS, 2003; ARNHEIM, 2004) que necessita ser bem planejado, ainda é, muitas vezes, tratado nos projetos como um elemento de segunda ordem.

Essa assertiva é norteada pelas seguintes questões:

1. Rangel et al. (2019) apontam que o conhecimento sobre a cor pelos projetistas (arquitetos e designers) advêm da empiria, uma vez que grande parte dos cursos de graduação não têm essas disciplinas;

2. a cor nos projetos ainda é muito pautada em seu componente estético (TEIXEIRA, 2015; ELY, 2016);

3. não há, de forma geral, interação dos projetos de arquitetura e design desde o início do planejamento da edificação, sobretudo em hospitais, cujas edificações sofrem contínuas modificações (RANGEL, 2016);

4. a pesquisa com o usuário que promova a interação cor $x$ usuário $x$ ambiente construído hospitalar, é considerada complexa demais, ou não importante, ou realizada sem o aporte da ergonomia, e as vezes ao final do projeto (RANGEL, 2016);

5. tenta-se resolver falhas da arquitetura e dos elementos que compõe os ambientes, os quais interferem negativamente na orientação espacial, apenas com placas e com uma sinalização que é um aposto aos demais projetos (BARA, 2019).

Nesse contexto é pertinente destacar a necessidade de ampliar a pesquisa da cor e do usuário sob o olhar da ergonomia, no âmbito do projeto do ambiente construído hospitalar. Aqui o destaque é a cor e sua força comunicativa para a auxílio à orientação espacial.

\section{A COR NA INFORMAÇÃO DO AMBIENTE CONSTRUÍDO HOSPITALAR}

O ambiente construído hospitalar é composto por setores e ambientes que possuem especificidades que impõem um modus operandi com carga de riscos, estresse e sentimentos diversos. Mediante a essa setorização bem definida quanto à funcionalidade dos setores e para contribuir com o estabelecimento do hospital terapêutico, que visa o bem-estar do usuário para a promoção da saúde (FOCAULT, 1979 apud TOLEDO, 2002), o uso da cor assume os aspectos estético, terapêutico, informacional e de higiene (RANGEL, 2016). 


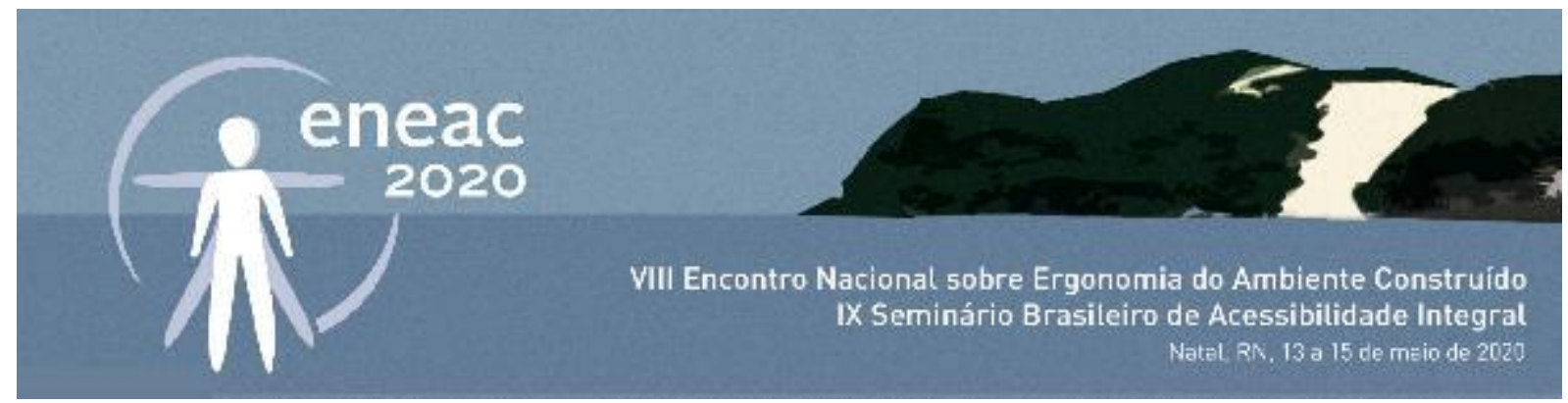

Para a orientação espacial, a cor emerge em seu aspecto informacional, ou seja, é a cor-informação, cuja premissa é organizar, hierarquizar e atribuir significado à informação (GUIMARÃES, 2006). Nesse contexto, a cor irá demarcar zoneamentos funcionais, marcos referenciais, vias de circulação e conectores que atuam como "chaves de leitura" do ambiente (LYNCH, 2006 apud RANGEL, MONT'ALVÃO, 2015).

As figuras 1, 2, 3 e 4 apresentam exemplos da participação da cor na construção de chaves de leitura.

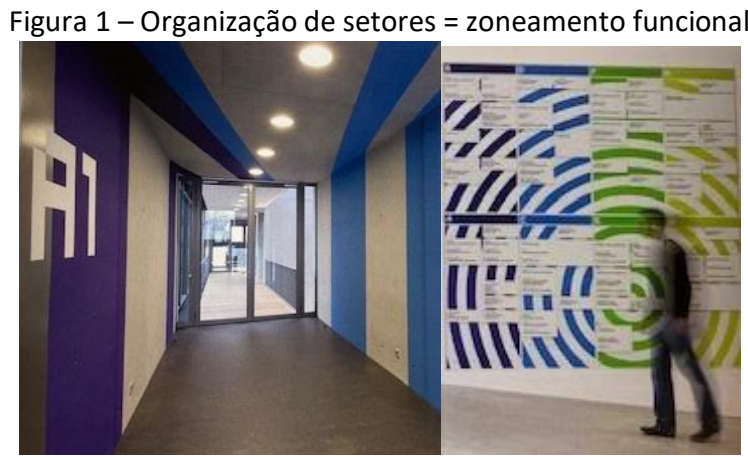

Fonte: Two points.net (2010)

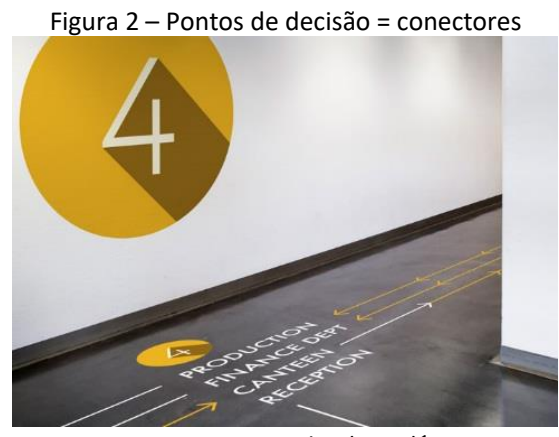

Fonte: MXDisplay (2017) ${ }^{1}$

Figura 3 - Destaque para elementos do ambiente = marco referencial

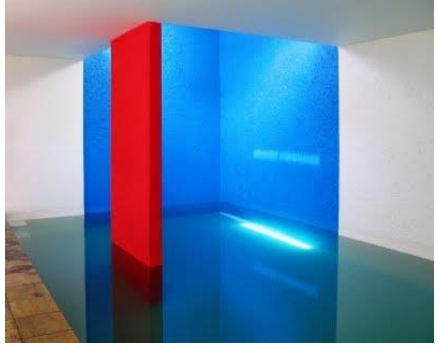

Fonte: Rangel (2011)

\footnotetext{
${ }^{1}$ Disponível em: < https://mxdisplay.co.uk/wayfinding-signage-floor-graphics/>. Acesso em: 12 jan. 2020.
} 


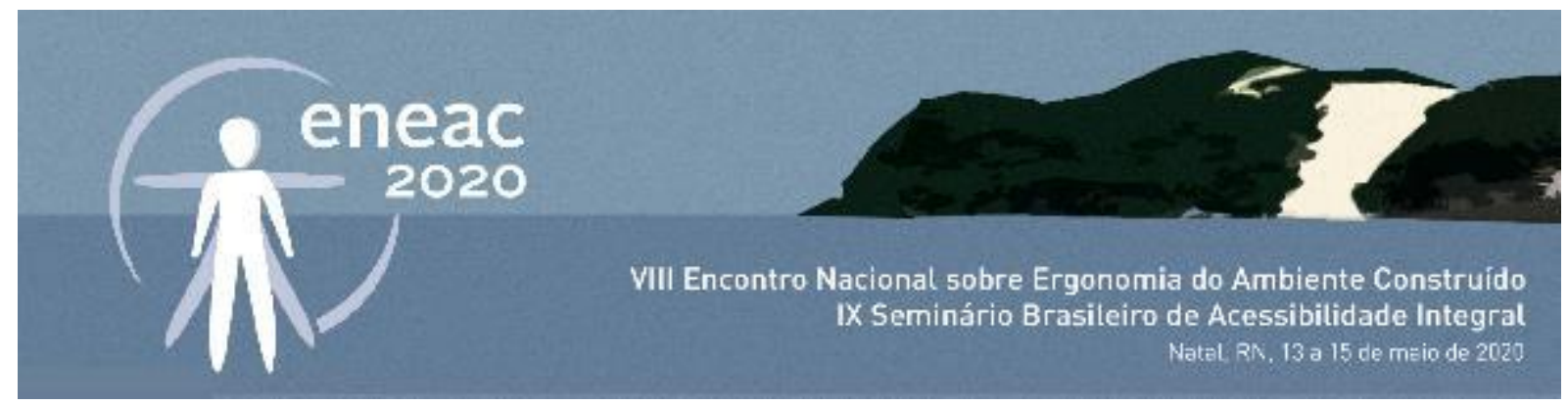

Figura 4 - Direcionamento em corredores e caminhos = vias de circulação

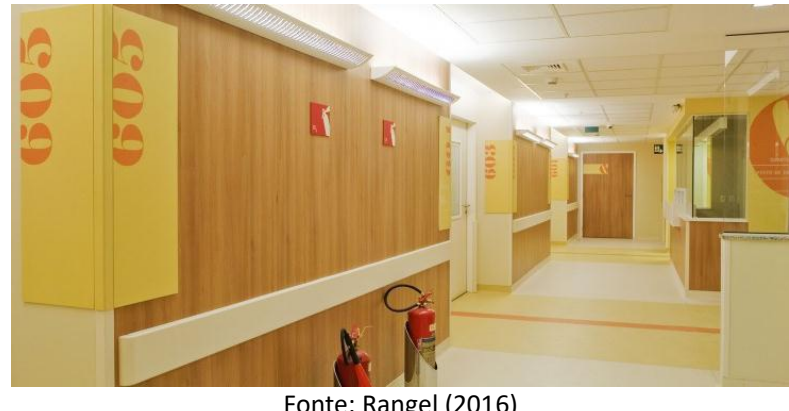

A partir dos exemplos supracitados, percebe-se que o suporte para a cor na orientação espacial extrapola os totens e as placas. Todos os elementos que compõe o ambiente construído hospitalar podem interferir auxiliando ou não na orientação espacial do usuário. Esses elementos ainda precisam dialogar harmonicamente entre si.

Nesse sentido, há necessidade de integração entre os projetos de arquitetura e de design, uma vez que para a orientação espacial, o ambiente construído precisa delinear um arranjo espacial com sequência de informação. Essa medida auxilia aos usuários a acionarem e/ou formarem seus mapas mentais, e tomarem uma decisão, formularem um plano de ação e executarem a decisão tomada.

Bins Ely (2004) corroborada por Ribeiro (2009) e Rangel (2016), aponta que os ambientes possuem uma rede informacional e interdependente composta pelos sistemas informacionais do ambiente construído, que se apresentam em três categorias: arquitetura (representado pelos elementos arquitetônicos); objetos (representado pelos objetos decorativos, mobiliário e equipamentos do ambiente) e mensagens adicionais (todas as mensagens com cunho informativo que auxiliam na interação humano/ambiente).

A cor participa ativamente dessa rede. Como cor-informação é ativa, pois se sobrepõe aos outros aspectos na construção das mensagens (códigos) que indicam um caminho e/ou o destino; mas também é passiva, pois atua nas esferas da estética, terapêutica e de higiene para harmonizar o ambiente, interagir e não concorrer com a informação para a orientação espacial.

As figuras 5 e 6 apresentam exemplos da cor-informação participando dos sistemas informacionais arquitetura e mensagens adicionais/sinalização.

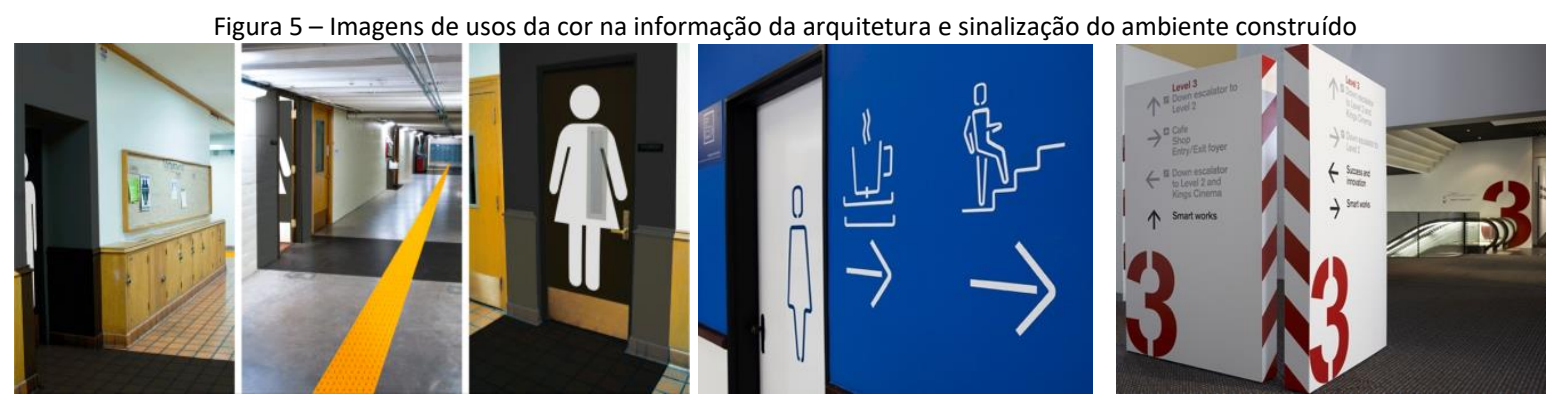

Fonte: Two points.net (2010) 

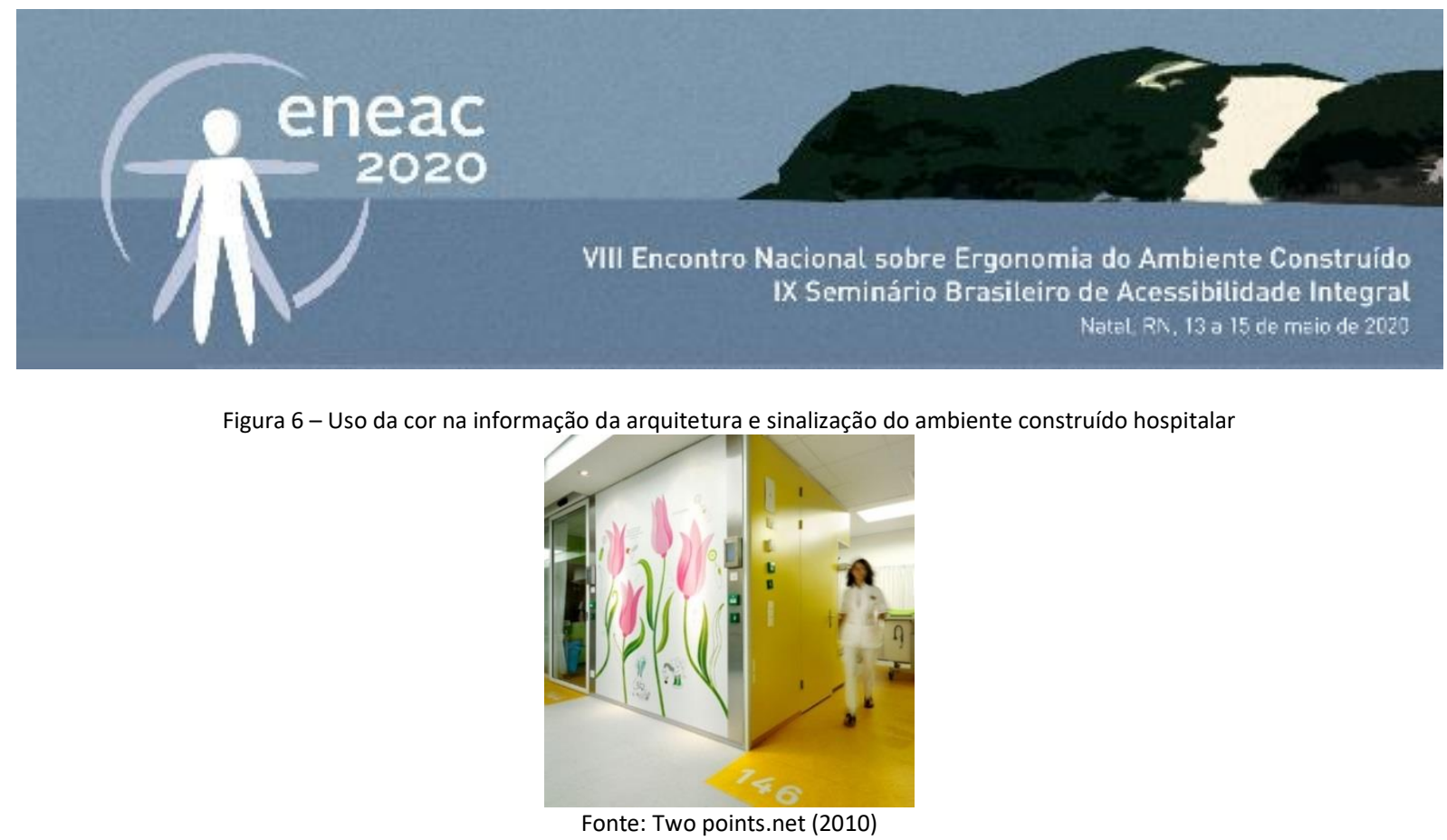

Verifica-se pelos exemplos apresentados, que a "cor passiva" não significa falta de estímulos visuais, uma vez que harmonia não é sinônimo de monotonia, e sim do controle das forças compositivas baseadas em unidade e variedade de formas, cores e luzes (ARNHEIM, 2004). Kükelhaus (APUD MERWEIN et al. 2007, p85) aponta que "as pessoas precisam de um campo biológico de tensão, elementos de contraste e estimulação provida pela variedade". A abstenção de tais campos de tensão produz desregulação desencadeada pela baixa estimulação, tal como luminosidade sem sombras, falta de variação de temperatura, circulação restrita, materiais ou cores monótonas.

Partindo da compreensão da interação usuário x ambiente construído x cor, pode-se apontar algumas premissas que indicam aspectos fundamentais para o desenvolvimento de um projeto de cor (MERWEIN, et al., 2007; RANGEL, 2016). Essas premissas estão listadas a seguir:

1. análise sistemática do ambiente - seus aspectos funcionais, culturais, sociais e emocionais questões materiais e imateriais do espaço;

2. análise sistemática dos usuários - questões físicas, emocionais e culturais na interação com o espaço;

3. análise sistemática da cor com o usuário e com o ambiente construído. As qualidades físicas, estéticas, simbólicas, terapêuticas e informacional da cor na:

a. relação usuário/cor - requerimentos físicos, fisiológicos e psicológicos vinculados ao usuário e, consequentemente à cor.

b. relação cor/ambiente construído - o espaço, as funções e os arranjos espaciais e os seus elementos coloridos.

c. relação cor/usuário/ambiente construído - visibilidade, legibilidade, usabilidade, agradabilidade e a tarefa.

Merwein, et al. (2007) postulam as premissas como uma base para uma discussão mais detalhada, ou seja, o ponto de partida para os desdobramentos segundo as especificidades e as variáveis do projeto.

Uma vez que a cor no ambiente construído hospitalar está envolta em uma diversidade de variáveis, é necessário um planejamento dos seus usos e as necessidades da cor para cada setor e para os 


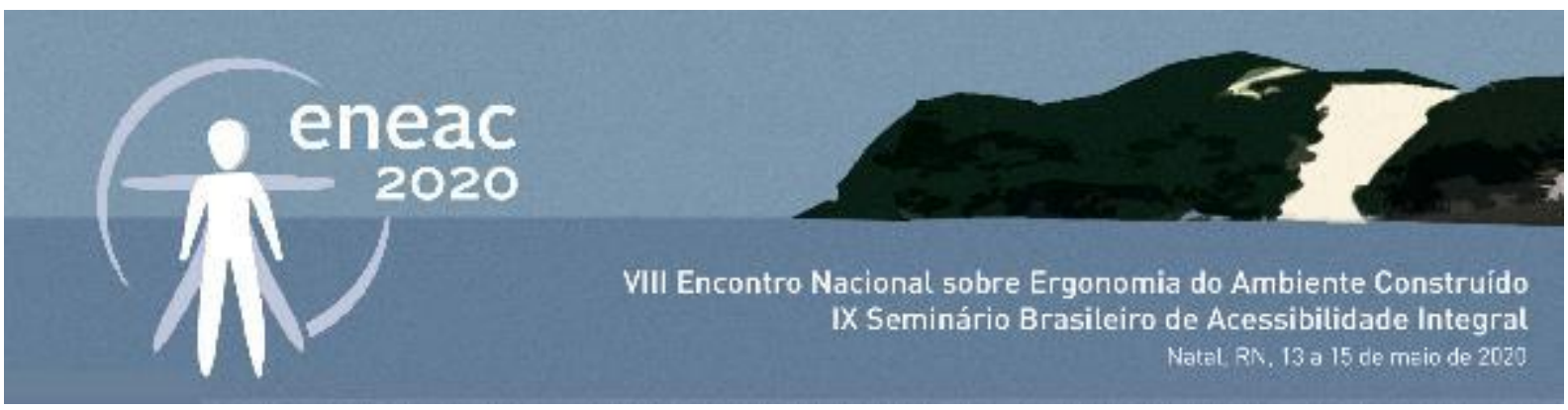

variados tipos de usuários. Portanto, não se pode pensar em um conjunto de regras como uma receita a ser replicada, muito menos para todos os ambientes e setores da instituição.

Sob os postulados da Ergonomia, Rangel (2016) desenvolveu o modelo denominado de Projeto Cromático para os sistemas informacionais (PCSI). O PCSI organiza os temas com os quais um projeto de cores deve lidar quando se volta à orientação espacial. É um modelo que se propõe aberto para agregar diversas questões relativas à cor-informação, aos usuários e ao ambiente construído, com o fim de auxiliar a orientação espacial e, consequentemente, o senso de lugar e os deslocamentos no ambiente construído hospitalar.

A figura 7 apresenta o modelo Projeto Cromático para os sistemas informacionais (PCSI).

Figura7: PCSI

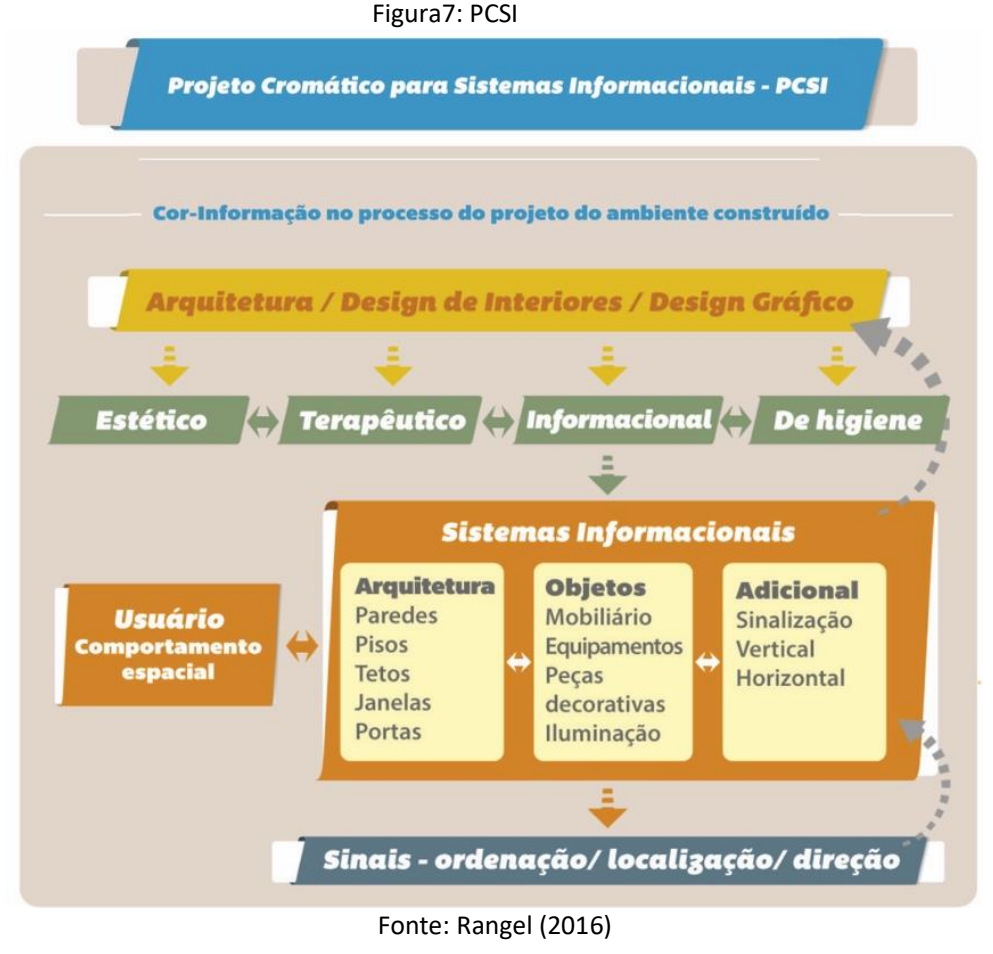

O PCSI tem como ponto fundamental a interação e a integração (1) das equipes de projeto de Arquitetura e Design, (2) da cor com o usuário, (3) da cor com o ambiente construído e (4) do ambiente construído com o usuário. Dessa forma, a cor, o usuário e os sistemas informacionais, são três temas em que as mesmas questões são observadas por cada projeto, à luz de suas especificidades e em acordo com as equipes.

Assim, cada tema é uma fase de projeto, mas que não se caracteriza como um momento com início, meio e fim, e muito menos, as fases são trabalhadas sequencialmente. As questões são vistas, revistas e discutidas em decorrência dos problemas e soluções surgidos, o que indica a permeabilidade dos limites entre as fases, uma vez que estas interpenetram-se e interagem entre si. 


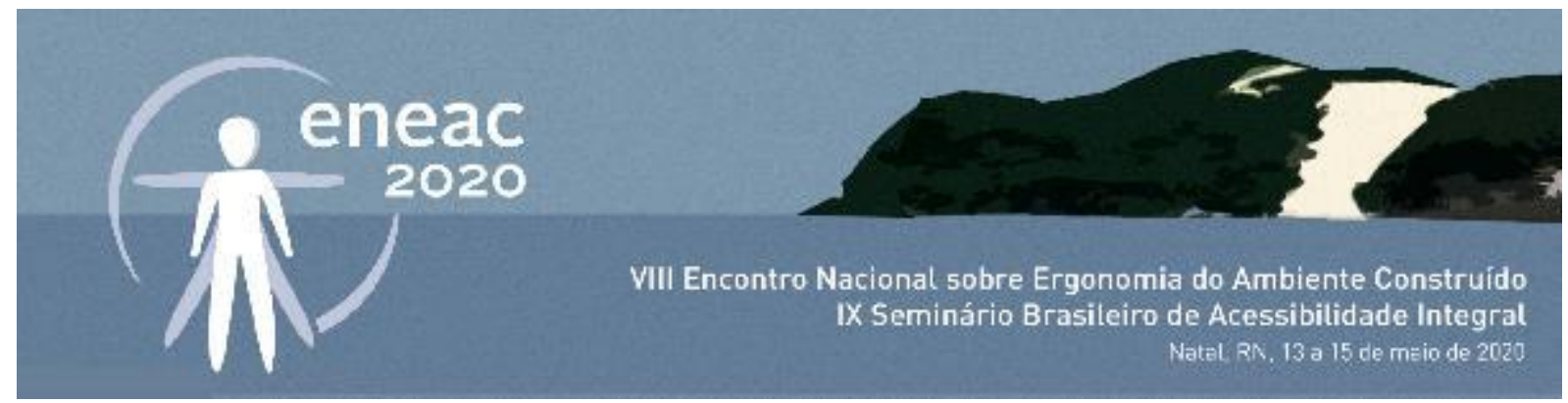

Dessa forma, há necessidade das equipes dos projetos de Arquitetura e de Design trabalharem em constante diálogo desde o início do processo de seus projetos.

Para tal é necessário observar:

1. o conhecimento teórico e prático da cor e da cor-informação;

2. a pesquisa com o usuário sob as bases da Ergonomia, ou seja, investigação com métodos e técnicas para levantar a opinião e o comportamento espacial do usuário ao realizar a tarefa;

3. a pesquisa do (e/ou no) ambiente construído, ou seja, o mapeamento do ambiente em seus quesitos materiais e imateriais;

4. o feedback em todos os passos do modelo.

Postula-se ser imprescindível a pesquisa do ambiente construído e do usuário, para a compreensão das questões influenciadoras no projeto da cor.

\section{A PESQUISA DA COR NO AMBIENTE CONSTRUÍDO HOSPITALAR}

Muitos profissionais especialistas em projetos do ambiente construído, tais como arquitetos e designers prescindem da pesquisa com o usuário por dois motivos principais: (1) acreditam que seu conhecimento sobre o ambiente, os materiais e as pessoas de um modo geral são suficientes; (2) acreditam que a pesquisa com o usuário demanda muito tempo de projeto e é cara, e o cliente não quer arcar com esses custos (RANGEL, 2011 e 2016).

Quanto à cor, os especialistas, conforme visto no item anterior, não possuem, de forma geral, um arcabouço sólido de conhecimento, e não veem a necessidade de um estudo mais detalhado para o seu uso (RANGEL et al., 2019).

Ghamari; Amor (2016) fizeram uma análise de diversas pesquisas sobre a cor no ambiente construído hospitalar, abarcando inúmeros fatores relativos às cores nesses ambientes. Em uma visão geral de seu estudo, a cor afeta os resultados da assistência médica, reduzindo erros médicos, promove a sensação de bem-estar, reduz o estresse, melhora o sono dos pacientes, reduz o tempo de permanência e a desorientação espacial. A cor ainda aumenta a satisfação do paciente, e a moral e a produtividade da equipe.

No entanto, para Ghamari; Amor (2016) é necessário trabalhar mais os dados para que se tenha maiores evidências quanto aos resultados. Isso significa dizer que as pesquisas devem ser replicadas, aumentando o número das amostras para que sejam validadas.

Como conclusão de seu trabalho, Ghamari; Amor (2016) apontam ser imprescindível o estudo e pesquisa da cor, e indicam a observação dos seguintes pontos:

1. a cor é um conceito complexo, pois se entrelaça com as condições de iluminação, vieses individuais e sua adequação a usos específicos; 


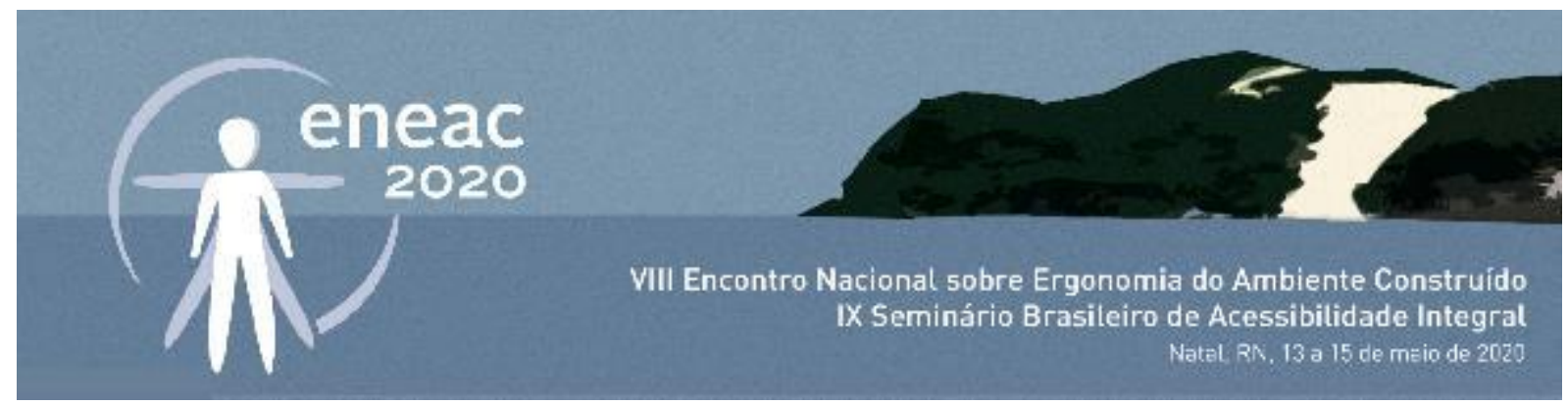

2. as pessoas podem avaliar, perceber e responder às cores em ambientes reais de maneira muito diferente dos testes de laboratório;

3. o significado da cor isolada e o significado do objeto colorido podem ser diferentes nos processos de percepção e, assim, encontrar correspondência entre uma cor e um objeto colorido pode ser questionável;

4. o corpo de conhecimentos sobre aplicação de cores é fragmentado e discutível, uma vez que muitos designers e profissionais de saúde questionaram as relações entre cor e pessoas, suspeitaram dos efeitos psicoterapêuticos da cor e buscaram um raciocínio empírico para as diferentes diretrizes de cores em ambientes de saúde;

5. raramente a pesquisa é replicada e a amostra ampliada para validar os resultados;

6. uma abordagem holística para entender a percepção de cores requer estudos que incluam a interação e a inclusão da pessoa e as condições ambientais simultaneamente.

Como contribuição à pesquisa da cor na orientação espacial do ambiente construído hospitalar, apresenta-se a seguir no quadro 1 , técnicas de levantamentos de dados vinculadas à pesquisa dos temas do modelo PCSI.

Quadro 1: Técnicas de levantamento de dados do PCSI

\begin{tabular}{|c|c|c|}
\hline MODELO PCSI & TÉCNICAS & OBJETIVOS \\
\hline $\begin{array}{c}\text { Interação entre os projetos de } \\
\text { arquitetura, design de interiores e } \\
\text { design gráfico. }\end{array}$ & \multirow{3}{*}{$\begin{array}{c}\text { Análise documental; } \\
\text { Entrevistas com a administração da } \\
\text { instituição; } \\
\text { Entrevistas com arquitetos e } \\
\text { designers de hospitais. }\end{array}$} & \multirow{3}{*}{$\begin{array}{l}\text { Verificar o estado da arte do } \\
\text { desenvolvimento de projetos de } \\
\text { arquitetura e design no que tange } \\
\text { à cor, usuários e orientação } \\
\text { espacial no ambiente construído } \\
\text { hospitalar. }\end{array}$} \\
\hline A cor nos projetos. & & \\
\hline A voz do usuário nos projetos. & & \\
\hline $\begin{array}{c}\text { Funções de uso da cor: estético, } \\
\text { terapêutico, informacional e de } \\
\text { higiene. }\end{array}$ & \multirow{2}{*}{$\begin{array}{l}\text { Observação do ambiente; } \\
\text { Mapeamento do ambiente } \\
\text { construído com seus setores, fluxos, } \\
\text { circulações, pontos nodais, cores e } \\
\text { posicionamento da sinalização. } \\
\text { Levantamento fotográfico. }\end{array}$} & $\begin{array}{l}\text { Verificar os locais e usos da cor no } \\
\text { ambiente construído hospitalar; }\end{array}$ \\
\hline $\begin{array}{l}\text { Interação entre os sistemas } \\
\text { informacionais no ambiente } \\
\text { construído. }\end{array}$ & & $\begin{array}{c}\text { Conhecer a lógica setorial do } \\
\text { ambiente construído, bem como } \\
\text { as vias projetadas (caminhos e } \\
\text { corredores) e as vias que os } \\
\text { usuários estabelecem ao } \\
\text { interagirem com o ambiente; } \\
\text { Conhecer e compreender a lógica } \\
\text { do arranjo espacial e da } \\
\text { sinalização e sua participação na } \\
\text { interação com os eventos do } \\
\text { ambiente. }\end{array}$ \\
\hline $\begin{array}{c}\text { Interações entre os sistemas } \\
\text { informacionais e o comportamento } \\
\text { do usuário. }\end{array}$ & $\begin{array}{l}\text { Questionário. } \\
\text { Observação das movimentações } \\
\text { com registros de comportamento } \\
\text { (em planilhas e fotográfico). }\end{array}$ & $\begin{array}{l}\text { Levantar a opinião do usuário } \\
\text { acerca do ambiente construído do } \\
\text { hospital, como também a } \\
\text { eficiência de suas movimentações } \\
\text { e da realização de sua tarefa; } \\
\text { Verificar o comportamento do } \\
\text { usuário na sua tarefa de saber } \\
\text { onde está, como se deslocar e } \\
\text { chegar ao seu destino. }\end{array}$ \\
\hline
\end{tabular}

Fonte: Rangel (2016) 


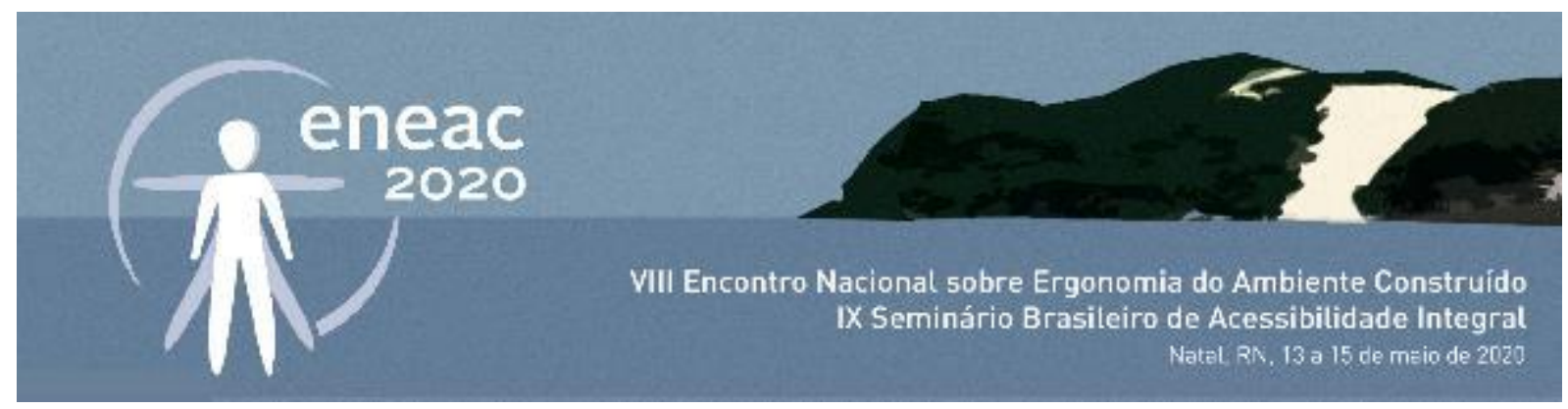

\section{CONSIDERAÇÕES}

Albers afirmou que "a cor é o meio mais relativo dentre os mais utilizados na arte" (ALBERS, 2009, p.15). Essa assertiva encontra consonância na comunicação visual, pois Albers (2009) demonstra que uma cor interage com as outras cores de seu entorno, alterando a sua percepção. Isso decorre do entendimento de que a visualização e processamento da cor pelo usuário, estão ligados à percepção humana, que por sua vez está vinculada a condicionantes físicas, fisiológicas, emocionais e simbólicas do usuário, e a condicionantes do ambiente da cor.

Essa complexidade é ampliada quando se pensa em aliar ambientes construídos hospitalares, usuários, tarefas e cores. Conforme apontado nos itens desse trabalho, cada um desses temas possui um conjunto de questões a serem levantadas, analisadas e compatibilizadas pelos projetos.

A informação para a orientação espacial é construída nas primeiras decisões de um planejamento arquitetônico, nas definições do partido, dos setores, dos caminhos e dos materiais coloridos. $O$ uso das cores e seu posicionamento nos elementos da arquitetura, dos objetos e da sinalização, devem estar pautados numa logicidade que auxilie os usuários a compreenderem os caminhos e destinos, mas também respeitando as especificidades do ambiente, que necessita prover, conforme Focault (apud TOLEDO, 2002) bem-estar físico e emocional aos usuários.

Diante desses aspectos é necessário que a cor não seja tratada como algo natural do entorno humano, cuja manipulação esteja vinculada apenas às sensibilidades e habilidades dos projetistas, ou mesmo que não tenha fundamental importância no ambiente construído. Não existe abstenção de manipulação de cores nos projetos, uma vez que onde há luz e sombra, há cor e não cor.

É necessário corroborar a colocação dos projetistas referente às pesquisas com o usuário, o ambiente construído e as cores serem complexas e demandarem tempo. No entanto, essas pesquisas são necessárias, pois o espaço manipulado pelo design pode aparentar diversas coisas que transmitem mensagens que impactam os sentimentos, pensamentos, desejos, conhecimento e ações dentro de seus limites.

O conhecimento é o caminho para se conseguir mudar esse cenário que rejeita a pesquisa e minimiza a complexidade dos temas. Dessa forma, os cursos de arquitetura e design necessitam preparar melhor seus alunos nos aspectos teóricos e práticos dos usos das cores (TEIXEIRA, 2015; ELY, 2016), nos métodos e técnicas da ergonomia e na aceitação do projeto fluir em parceria, respeitando-se as especificidades de cada campo.

Além disso, a pesquisa da cor no ambiente construído hospitalar (e demais ambientes construídos), em seus diversos usos, necessita ser ampliada para que se possam validar métodos e técnicas mais adequados para a interação cor $\mathrm{x}$ usuário $\mathrm{x}$ ambiente construído. Entende-se que as variáveis complexidade e tempo possam ser minimizadas quando se ampliarem os resultados que comprovem a eficácia e eficiência da cor na interação humano $x$ ambiente.

O PCSI é um modelo referente à cor-informação na orientação espacial do ambiente construído que visa contribuir com essa lacuna do estudo e aplicação das cores no projeto. É interessante observar 


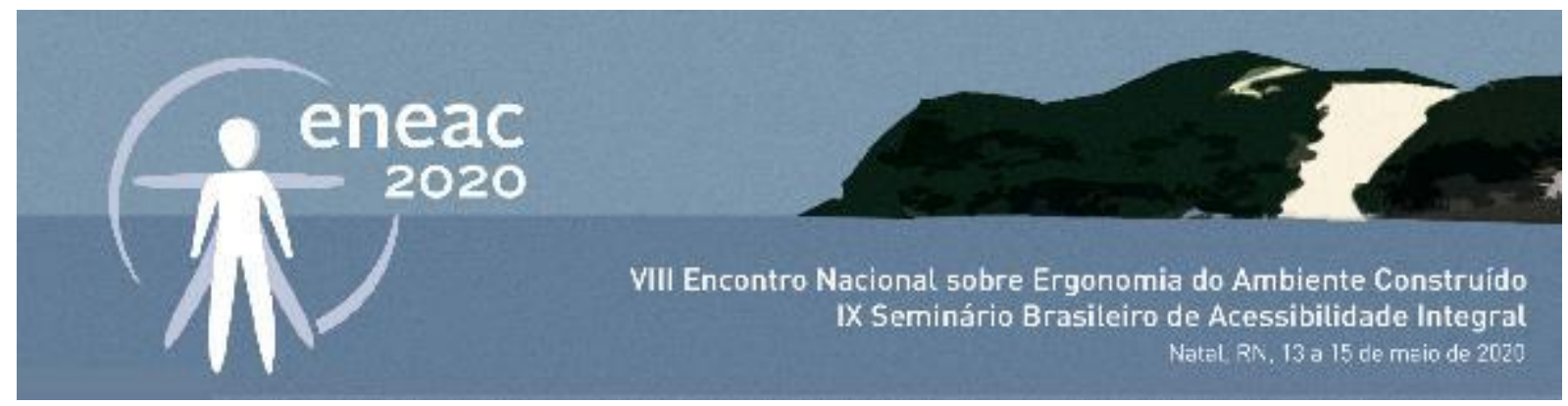

que o PCSI foi testado em dois ambientes construídos de hospitais, sendo os métodos e técnicas a ele vinculados, focados no levantamento de dados, e em ambientes reais com o usuário no desenvolvimento da tarefa. Os testes apontaram a pertinência do modelo.

No entanto, o modelo PCSI precisa ser aplicado em mais ambientes, e ainda, devem-se testar outras técnicas da percepção da cor pelo usuário em sua interação com os sistemas informacionais do ambiente construído hospitalar. Com mais resultados positivos, será possível validá-lo com suas técnicas e indicar seu uso no desenvolvimento de projetos.

Ao longo desse estudo foi visto que pesquisa da cor no ambiente construído e envolvendo tarefas e usuários é complexa e ainda demanda muitos estudos. Percebeu-se que a maior dificuldade no uso do PCSI está na interação e integração das equipes de arquitetura e design a partir das etapas iniciais do desenvolvimento do projeto do edifício, ou mesmo, em etapas que não sejam mais possíveis ao design discutir a respeito de aspectos relevantes à cor-informação e sua integração no ambiente.

\section{Referências}

ALBERS, J. A interação da cor. São Paulo: Martins Fontes, 2009.

ARNHEIM, R. Arte e percepção visual: uma psicologia da visão criadora: nova versão. Tradução de Ivonne Terezinha de Faria. São Paulo: Pioneira Thomson Learning, 2004.

BINS ELY, V. H. M. Acessibilidade espacial: condição necessária para o projeto de ambientes inclusivos. In: MORAES, A. (Org.). Ergodesign do ambiente construído e habitado: ambiente urbano, ambiente público, ambiente laboral. Rio de Janeiro: iUsER, 2004. p.17-40.

DONDIS, D. A. Sintaxe da linguagem visual. São Paulo: Martins Fontes, 2003.

ELY, C. Processo de seleção de cores no projeto de produto orientado ao bem-estar. 2016. 80f. Dissertação (Mestrado) Universidade Federal do rio Grande do Sul, Escola de engenharia, Porto Alegre, BR-RS, 2016.

GHAMARI, H.; AMOR, C. The Role of Color in Healthcare Environments, Emergent Bodies of Evidence-based Design Approach. Sociology and Anthropology, ano 11, abr. 2016: 1020-1029. Disponível em: < http://www.hrpub>. Acesso em: 25 set. 2018.

GATTÁS BARA, G. A. Orientação espacial em ambientes hospitalares: wayfinding. 2019. Dissertação (Mestrado em Ambiente Construído) - Universidade Federal de Juiz de Fora, Programa de Pós-graduação em Ambiente Construído, Juiz de Fora, 2019.

GUIMARÃES, L. O repertório dinâmico das cores na mídia: produção de sentido no jornalismo visual. In: ENCONTRO DA COMPÓS DA UNESP, 15., 2006. Bauru. Anais... Bauru: Unesp, 2006 Disponível em: <http://www.unicap.br/gtpsmid/pdf06/luciano-guimaraes.pdf> Acesso em: 15 mai. 2014.

LAWSON, B. Como arquitetos e designers pensam. São Paulo: Oficina de Textos, 2011.

MEERWEIN, G.; RODECK, B.; MAHNKE, F. H. Color: communication in architectural space. Boston: Birlkäuser, 2007.

MONT'ALVÃO C.; VILLAROUCO, V. Apresentação. In: Um novo olhar para o projeto: a ergonomia do ambiente construído. Teresópolis: 2AB, 2011.

MORAES, A. de. Ergodesign do Ambiente Construído e Habitado. Ambiente urbano, Ambiente Público, Ambiente Laboral. Rio de Janeiro: iUsEr, 2004, 146 p. 


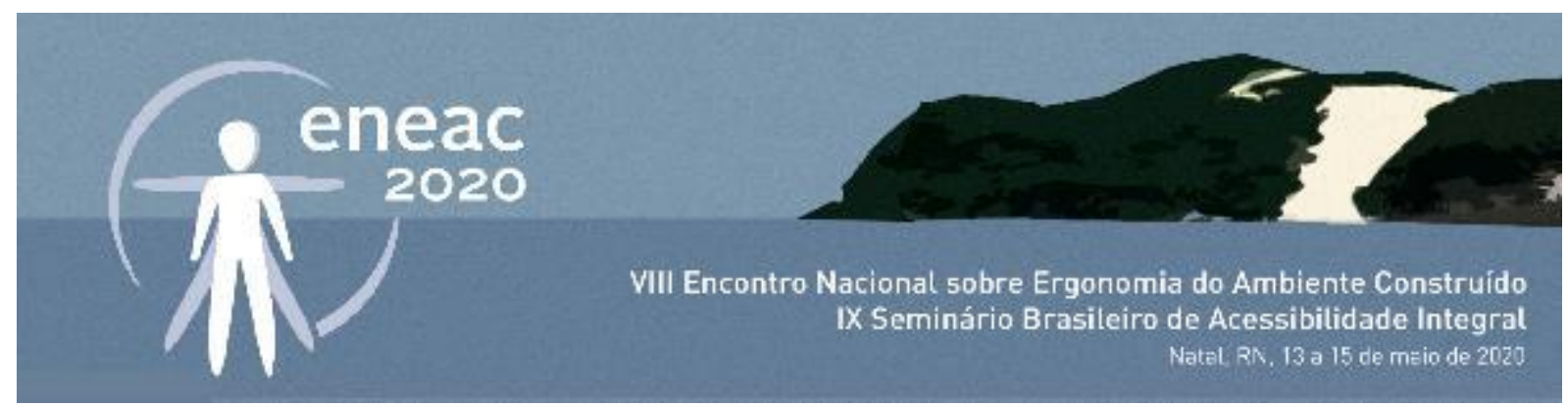

RANGEL, M. M. Cor e ergonomia do ambiente construído: uma investigação da orientação espacial em um ambiente hospitalar. 2011. 255f. Dissertação (Mestrado em Design) - Pontifícia Universidade Católica do Rio de Janeiro, Departamento de Artes e Design, Rio de Janeiro, 2011.

RANGEL, M. M. Projeto cromático para sistemas informacionais: proposta para o uso da cor em wayfinding para estabelecimentos assistenciais de saúde. 2016. 298f. Tese (Doutorado em Design) - Pontifícia Universidade Católica do Rio de Janeiro, Departamento de Artes e Design, Rio de Janeiro, 2016.

RANGEL, M. M.; DE OLIVEIRA CAMACHO, N. KUHN, S. P.; MENDES, L. Pesquisa exploratória com inquirições aos especialistas em projeto de produtos. In: $17^{\circ}$ ERGODESIGN - CONGRESSO INTERNACIONAL DE ERGONOMIA E USABILIDADE DE INTERFACES HUMANO TECNOLÓGICA: PRODUTO, INFORMAÇÕES AMBIENTES CONSTRUÍDOS E TRANSPORTE. 2019. Rio de Janeiro. Anais... Rio de Janeiro: PUC-Rio, 2019. Disponível em: https://www.proceedings.blucher.com.br/article-list/ergodesign20193030/list\#articles. Acesso em 20 jan. 2020.

RANGEL, M. M. MONT'ALVÃO, C. A observação do comportamento do usuário para o wayfinding no ambiente construído. Estudos em Design | Revista (online). Rio de Janeiro: v. 23 | n. 3 [2015], p. 166 - 180 | ISSN 1983-196X

RANGEL, M. M. MONT'ALVÃO, C. O projeto hospitalar cores e normas. In: 10 CONGRESSO BRASILEIRO DE PESQUISA E DESENVOLVIMENTO EM DESIGN, 2012. São Luís. Anais... Florianópolis: UFMA, 2012.

REQUENA, G. Habitar híbrido: subjetividades e arquitetura no lar da era digital. São Paulo: Editora Senac, 2019.

RIBEIRO, L. G. Onde estou? Para onde vou? Ergonomia do ambiente construido: wayfinding e aeroportos. 2009. 266f. Tese (Doutorado em Design) - Pontifícia Universidade Católica do Rio de Janeiro, Departamento de Artes e Design, Rio de Janeiro, 2009.

TEIXEIRA, A. R. V. M. T. A cor enquanto elemento no projecto do design de produto. 2015. 182f. Dissertação (Mestrado em Design) - Universidade de Lisboa, Faculdade de Belas Artes, 2015.

TOFLE, R. B. et al. Color in healthcare environments. USA: The Coalition for Health Environments Research (CHER), 2004. Disponível em: <http://www.CHEResearch.org> Acesso em: 10 set. 2012.

TOLEDO, L. C. Feitos Para Curar. Arquitetura Hospitalar e Processo Projetual No Brasil. Dissertação de Mestrado. Rio de Janeiro: UFRJ/PROARQ/Programa de Pós-Graduação em Arquitetura, 2002. 184p.

TWOPOINTS.NET (Eds.) Left, right, up, down: new directions in signage and wayfinding. Berlim: Gestalten, 2010.

VILLAROUCO, V. (2001) Modelo de avaliação de projetos. - enfoque cognitivo e ergonômico. Tese. PPGEP-UFSC. Florianopolis. 